\title{
The Mystery of the Triceratops's Mother: How to be a realist about the species category.
}

Adrian Currie

Penultimate Version, forthcoming in Erkenntnis

\begin{abstract}
Can we be realists about a general category but pluralists about concepts relating to that category? I argue that paleobiological methods of delineating species are not affected by differing species concepts, and that this underwrites an argument that species concept pluralists should be species category realists. First, the criteria by which paleobiologists delineate species is 'indifferent' to the species category. That is, their method for identifying species applies equally to any species concept. To identify a new species, paleobiologists show that interspecies processes, such as phenotypic plasticity (including pathology), sexual dimorphism, or ontogenetic diversity, are a worse explanation of the variance between specimens than intraspecies processes. As opposed to operating under a single or plurality of species concepts, then, paleobiologists use abductive inferences, which would be required regardless of any particular species concept. Second, paleobiologists are frequently interested in large-scale, longterm morphological patterns in the fossil record, and resolving the fine-grained differences which result from different species concepts is irrelevant at those scales. I argue that this claim about paleobiological practice supports what I call 'indifference realism' about the species category. The indifference realist argues that when legitimate investigation is indifferent to a plurality of concepts, we should be realists about the category those concepts pertain to.
\end{abstract}

\section{Introduction}


Some scientific or folk categories plausibly fail to be captured by a single concept. In such circumstances, what could licence realism about those categories? That is, what could lead us to take the category as an objective, mind-independent feature of the world? I will argue that one road to category-realism in the face of concept-pluralism is via 'indifference'. The category is necessary for some legitimate scientific (or other knowledge-producing) project, but the plurality of concepts attached to that category do not make a difference to how that project proceeds. I shall demonstrate 'indifference realism' in the species debate.

One way of being a concept pluralist about a scientific category is to demonstrate that there are at least two non-equivalent specifications of that category which each underwrite a legitimate research program. A 'specification' of a category divides up the world: who gets to be a member of that category, and how are within-category delineations made? For instance, the biological species concept is a specification of the species category, as it tells us that interbreeding populations count as species. In regards to species, pluralism is popular amongst philosophers of biology —although, as we shall see, there is significant disagreement about a further question. Namely, ought we be realists about the species category, or ought it be abandoned in favour of a group of more specific categories or particular taxa? I will introduce a different kind of pluralism, and one which underwrites realism about the species category. The pluralism works like this: a category has at least two, non-equivalent specifications-however, there is a legitimate research programme which is 'indifferent' to those specifications. That is, it makes no difference to the programme's methodology which specification is preferred and, moreover, there is good reason to not bother with those specifications. This kind of pluralism, I argue, is seen in paleobiology. This leads to realism on the basis of the legitimacy of paleobiological investigation. Just as species concepts are legitimized by their use in various scientific endeavours, so is the species category legitimized by paleobiology. When I refer to

\footnotetext{
'But see Sober (1994), Wilkins (2003, 2009), Hull (1988), Ghislen (1987).
} 
'realism', then, I will usually mean realism about a general category—species—rather than about specific taxa.

The argument will proceed via a representative case study: the recent debate about the taxonomic relationship between two North American Ceratopsidae, Triceratops and Torosaurus. As we shall see, paleobiologists determine phylogenetic relationships on an explanatory basis. In order to establish a new species, they must show that the divergences between specimens which are possibly due to separate evolutionary histories are not better explained by within-species variation. Their criteria are 'indifferent', in a sense I will define, to the species category. Moreover, I shall argue that this indifference is not merely due to paleobiologists lacking finegrained information about the past: in some cases their indifference is due to their explanatory interests.

I shall, then, make a claim about paleobiological practice: species delineations are made on explanatory grounds and are indifferent to the species category, that is, differing species concepts do not make a difference to their method. From this claim, I shall make metaphysical hay via what is, in effect, a parity of reasoning argument. Many pluralists are realists about the taxa picked out by species concepts on the basis of the legitimacy of scientific practice. They appeal to a link between successful employment in scientific investigation and ontology. I'll argue that paleobiological use of species is indifferent to—ranges over-different species concepts, and is moreover legitimate. This suggests that we should be realists about the general species category.

Although this paper is clearly geared towards philosophical debate about species and realism about categories in general, it does have an important insight for paleobiologists who might be less concerned with that issue. In conversation at least, paleobiologists sometimes express concern about varying species concepts: they are very aware of the ambiguity of 'species'. The argument in section 4 should put their minds to rest about this: even though 'species' can be 
ambiguous, it is not ambiguous in a way which matters to paleobiological investigation (indeed, as we'll see, paleobiological discussion of ‘species' often isn't ambiguous at all!).

\section{Pluralism \& Realism}

Let's begin by sketching the debate. A traditional species pluralist holds that there are at least two, non-equivalent, and equally legitimate species concepts. Many philosophers of biology agree $^{2}$. It is more contentious whether pluralists can be realists about the species category. That is, whether the category itself is part of mind-independent, objective reality. I'll first sketch two examples of species concepts which potentially meet the pluralist's criteria, before shifting to the debate about category realism.

It is important to distinguish pluralism from the view that anything goes: the idea that species are just whatever scientists say they are, that is, that there are no ontic or epistemic constraints on species-concepts. For the pluralist, although there is a plurality of species concepts, not just any will do. Concepts are granted legitimacy by playing some ineliminable role in a research programme which is itself legitimate. There are, then, three ways of denying pluralism: by demonstrating that species concepts are equivalent, by arguing that species concepts are eliminable, or by denying the legitimacy of the corresponding research programme. As we'll see, for pluralists, claims about different concepts often gain ontological force in virtue of their scientific legitimacy.

Let's compare two species concepts. The biological species concept takes species to be reproductively isolated groups. To find out whether two organisms are of the same species, I need to know facts about their group-membership, and the extent to which those groups interbreed ${ }^{3}$. The phylogenetic species concept takes species to be ancestral individuals, that is,

\footnotetext{
${ }^{2}$ For instance, Kitcher (1984), Mishler \& Brandon (1987), Dupre (1999), Ereshefsky (2001), Reydon (2004), O'Malley \& Dupre (2007).

${ }^{3}$ See Mayr (1942), Dobzhansky (1937), Paterson (1985) and Ghiselin (1987) for variations.
} 
organisms are the same species in case they share relevant ancestors. Here, I need to know facts about the organisms' evolutionary histories to know about species membership. These concepts are non-equivalent ${ }^{4}$. To take a simple example, asexual organisms (depending on how we define 'reproduction') do not sexually reproduce, and so on the face of it are each species unto themselves by the biological concept ${ }^{5}$. However, they do form meaningful ancestral groups, and so by the phylogenetic concept can be considered species. Moreover, it is plausible that these non-equivalent concepts are better suited to some research programs than others. Again, the biological species concept (at least naively) looks next to useless for asexual taxa, whereas a phylogenetic approach has, perhaps, some legs. In other contexts, the biological species concept could be more applicable. For instance, phylogenetic species concepts restrict species to monophyletic groups, however there is sometimes reason to admit paraphyletic groups as legitimate taxa. For instance, even-toed ungulates are a paraphyletic group, as monophyly would require the addition of cetacea. However, given their morphological and environmental divergence from their land-locked cousins, excluding whales and dolphins is surely legitimate in some contexts (see Funk \& Ormland 2003 and Ereshefksy 2001 for species-level examples). Whether either of these are ineliminable from their prospective projects is a more difficult question: perhaps one could be ultimately abandoned, or the work could be done by some other species concept, at which point pluralism would fail.

An argument for species pluralism, then, demonstrates that two concepts are nonequivalent, and play ineliminable roles in legitimate research projects. Let's imagine that we are convinced by arguments for pluralism about species concepts. That is, we believe in the legitimacy of a plurality of species concepts—such as the biological and phylogenetic. Moreover, let us accept the realist connection between legitimate scientific practice and ontology. Roughly,

\footnotetext{
${ }^{4}$ See Avise \& Wollenberg (1997) and Baum \& Shaw (1995).

${ }^{5}$ Again, this is an extremely simplified discussion, see Andam et al (2010), Bapteste \& Burian (2010), Bapteste et al (2009) and Ereshefsky (2010) for more details on the relationship between species concepts, eukaryotes and other asexual organisms.
} 
if a concept is successfully employed in a legitimate science, this gives me licence to be a realist about the category or kind that the concept delineates. For instance, if the phylogenetic species concept meets this criteria, then I am given leave to believe both in that kind—ancestral, phylogenetic individuals—and in the specific taxa that concept picks out. There is, undoubtedly, a lot more to be said about the mechanics and plausibility of the link between scientific legitimacy and ontological realism ${ }^{6}$. I will take it that pluralists about species taxa are often so on the basis of such a link, and that is all I need for the parity of reasoning argument in section 5 .

A further question arises: what is the fate of the species category? In the face of concept pluralism, do we have grounds for believing that there is a general class or kind? Realists argue for retention, anti-realists for abandonment.

One kind of anti-realist argument focuses on the epistemological upshots of pluralism (Stanford 1995, Rosenberg 1994). According to species pluralism, the biological world is subject to many possible carvings, but we cannot establish whether any particular carving is the right one, and so we should remain agnostic about the general species category: one specification might, after all, be correct, but we can never know. Ereshefsky (1998) provides an anti-realist argument directly from disunity: there is an abundance of evidence that the biological world is correctly, and legitimately, carved into various base taxa, which we call 'species', but those taxa come in varying types. The problem, for him, is not a lack of information but an overabundance. Crucially, Ereshefsky drives his anti-realism about the general category by relying on the same link between scientific legitimacy and ontology which underlies pluralism. As he says,

... contemporary biological theory provides ample evidence that the tree of life is segmented by biological forces into different types of species taxa. Consequently, there is no single unitary species category, but a heterogeneous collection of base taxa referred to by the term 'species' (104).

\footnotetext{
${ }^{6}$ A good place to look for skepticism about such a link is Kyle Stanford's work, for instance his (2006).
} 
So, anti-realists argue either that, say, the clash between the biological and phylogenetic species concepts leads to an epistemological gap, undermining legitimate belief in 'species', or that the biological and phylogenetic species concepts carve out two real base taxa, but this means that 'species' picks out a disunified, and thus unreal, category.

For a promiscuous realist such as Dupre (1993), it is doubtful that picking out a heterogeneous, disunified class is any block to that class' existence and legitimacy. Some realists have responded by attempting to unify species. Brigandt (2003), for instance, argues that there is a general 'phenomena' of species, base-level biological patterns which require explanation, and that various species concepts are different explanans of that pattern. There is a unified pattern, 'species', but the pattern is produced by disunified processes, represented by the various concepts (see De Queiroz 1999 for another realist response which attempts to unify species as 'base taxa'). I am going to explore a different route to realism about the species category. As we shall see, the view emerges from a consideration of how paleobiologists identify taxa.

\section{The 'Toroceratops' Debate}

The Ceratopsidae were a diverse family of quadruped herbivorous dinosaurs, marked out by their distinctive beaks, shearing rows of back teeth and—most especially—their horns and crested frills. They lived at the close of the Mesozoic period, and (or so it was thought) at least two genera, Triceratops and Torosaurus, were present until the extinction event at the dawn of the Palaeogene. However, the relationship between Triceratops and Torosaurus has been questioned. By one view, the 'Toroceratops' hypothesis, they are representatives of different life stages of the same animal, while by the traditional view they are separate genera. I shall use this debate to illustrate how paleobiologists make taxonomic decisions, and the kinds of 
investigations these decisions inform. Note that although Triceratops and Torosaurus are genuslevel rather than species-level categories, the lessons carry over?.

Since their discovery in the late $19^{\text {th }}$ Century, Triceratops and Torosaurus were assigned separate genera. The two are distinguished morphologically, particularly by their distinctive 'frills'. Torosaurus frills are large and thin, sporting two 'holes', while Triceratops' are thicker and squatter (see fig.1). Moreover, Torosaurus are much rarer than Triceratops and tend to be larger: while Triceratops range in size from .5 to 2 meters tall, Torosaurus range from 2 to 3 meters.

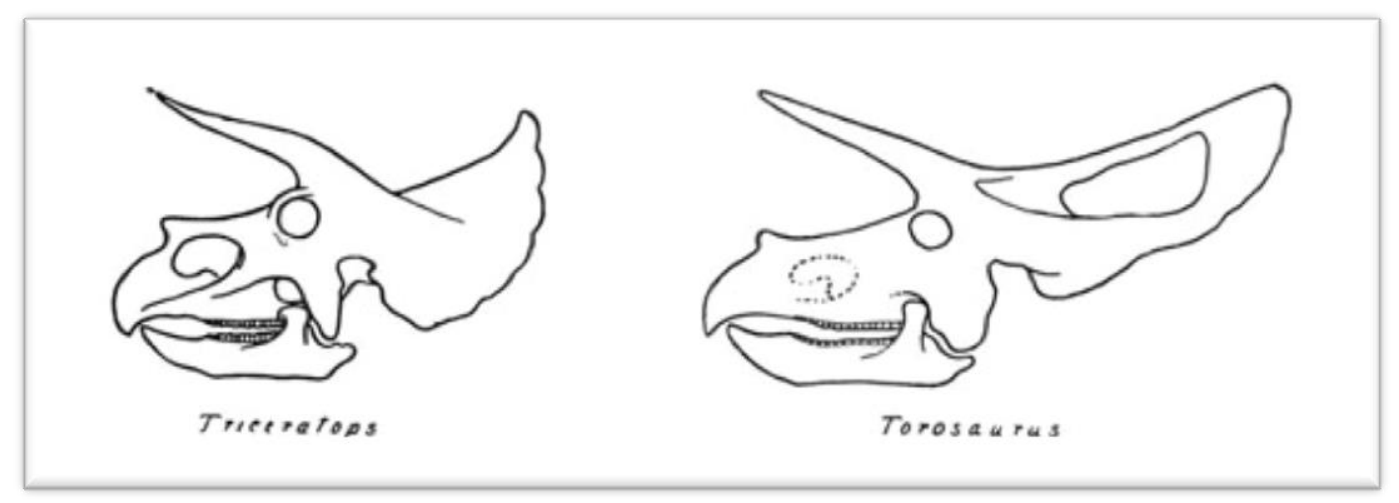

Figure 1: Triceratops vs Torosaurus skull (Image credit: Dinosaurs by W. D. Matthew (1915); public domain.)

In 2006, Horner \& Goodwin argued that the skull of Triceratops developed extensively during ontogeny $^{8}$. They identified four growth stages, each marked by systematic transformation of the skull. For instance, the Triceratops' distinctive horns leaned backwards towards the frill in juveniles, but switched to forward facing (as they are in figure 1) in young adulthood. If

\footnotetext{
${ }^{7}$ I skate over some subtlety here. Ereshefsky (2001) has pointed out that, if we don't think there is an interesting difference between species and higher taxa, this is a kind of species anti-realism. If that is right, then my argument is for taxa-category realism, rather than species-category realism. I am comfortable with this-realism about some category is fine with me: I won't quibble about whether we get to call them 'species'. I return to these points in 6.4.

${ }^{8}$ Speculating about extreme changes in dinosaur life-stages has become de-rigour. It has been suggested, for instance, that the enormous sauropods both led very different lives in their juvenile and adult stages, for instance it has been speculated that they switched from fast-growing endothermy to relaxed ectothermy mid-life (Farlow 1990). It has also been suggested that Tyrannosaurus rex had two distinctive ontogenetic stages, a juvenile stage characterized by fast running speeds and feathers, and a slow, featherless adult packing a major bite (see Currie 1998 \& Erickson et al 2004).
} 
Triceratops cranial development is highly plastic, then mistaking differences in life stages for differences in taxa is a real possibility. In 2010, Scannella \& Horner suggested just this.

Scannella \& Horner argue that specimens previously identified as 'Torosaurus' were, in fact, mature Triceratops. First, by extrapolating Horner \& Goodwin's developmental trajectory, they suggest that Torosaurus skull morphology is within Triceratops range. To abstract from the detail, Scannella \& Horner use Horner \& Goodwin's work as an ontogenetic model in order to project the Triceratops' developmental range over its life-span. For instance, squamosal (the bone at the back of the skull supporting the frill) elongation can be measured by comparing gross length against the ratio of squamosal length and width. Specimens of various ages can be plotted against these measurements. A line of best fit captures the four Triceratops life stages in sequence and, so they argue, Torosaurus (see fig 2).

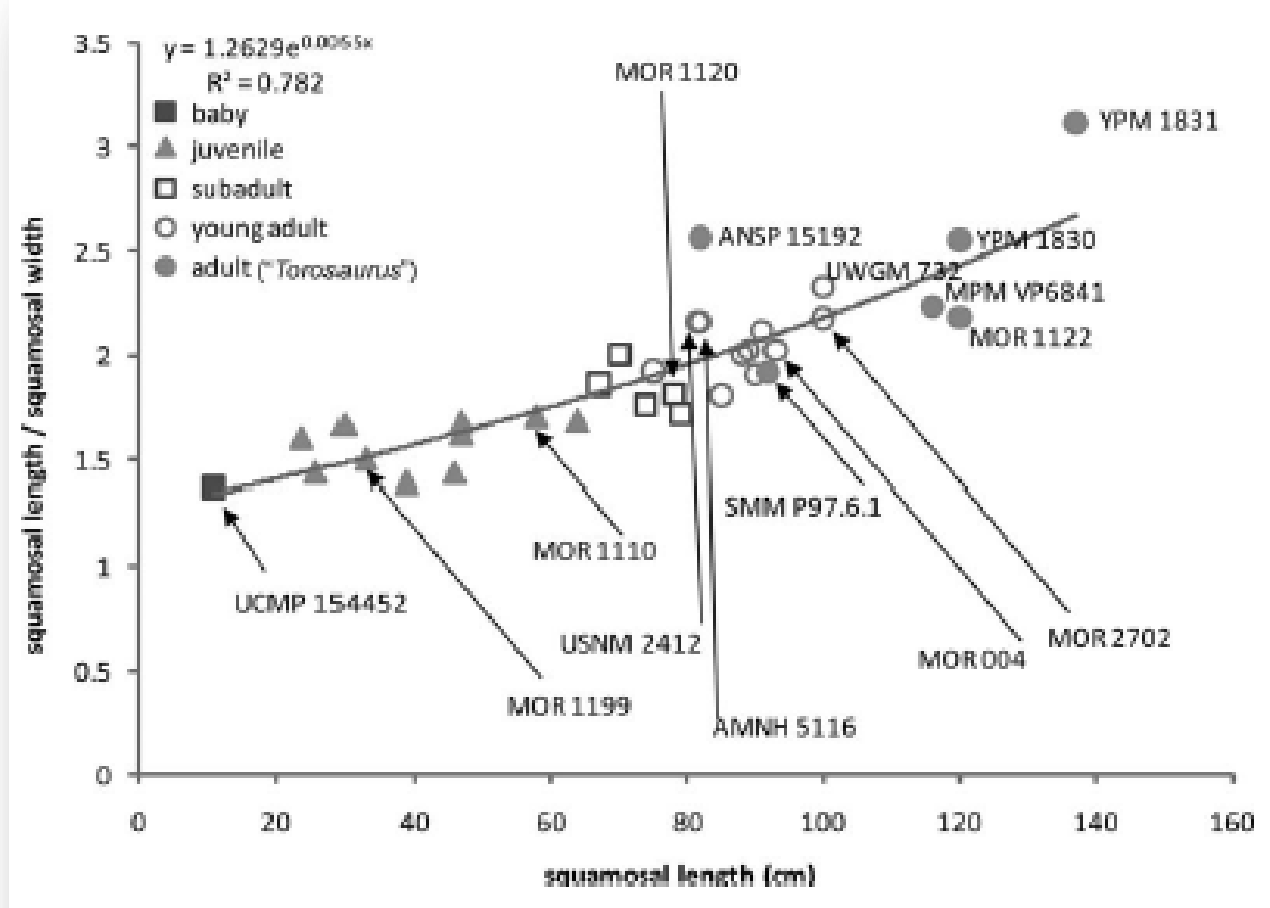

Figure 2: Squamosal elongation in Triceratops and Torosaurus (from Scannella \& Horner 2010, pp1161) 
Second, they undertook an osteohistological study. One way of identifying an organisms' age is via its cell tissue. Young animals have porous, primary tissue, while older animals' tissue is more condensed and they have more pronounced secondary osteons. Scannella \& Horner examined the horns of several specimens and found that Triceratops horns were invariably more youthful. Additionally, Scannella \& Horner cite the lack of juvenile Torosaurus, and their overlap in both location and strata, as further evidence. They also argue that some potentially youthful Torosaurus specimens have been misidentified.

There are several, important, challenges to the 'Toroceratops' hypothesis. First, is it developmentally plausible that the Triceratops frill would thin and develop holes as it grew into 'Torosaurus' adulthood? Although Horner \& Lamm (2011) and Scannella \& Horner (2011) point to the outlier Ceratopsidae, Nedoceratops, as a potential midway between the two, this is highly speculative. In other Ceratopsidae with thin, holed frills (such as Protoceratops) the holes are present from earliest frill development. Second, Maiorino, Farke \& Piras (2013) construct a Ceratopsidae skull morphospace by measuring skulls and plotting them along various dimensions of transformation. From that basis they develop several other 'developmental trajectories' similar to Scannella \& Horner's which place Torosaurus in different, non-Triceratops areas of morphospace. Third, Longrich \& Field (2012) examine Ceratopsidae of various ages and types to develop a general growth sequence, using this to identity both elderly Triceratops and juvenile Torosaurus. The hypothesis that 'Torosaurus' and 'Triceratops' are co-extensive is, at this point, open, but we've seen enough of the debate to draw some general lessons.

Taxonomic identification in paleobiology relies on explaining morphological patterns in the fossil record. That is, to claim two specimens are the same species, paleobiologists must claim that interspecies processes such as phenotypic variation are a better explanation of their differences than intraspecies processes from divergent evolutionary histories. In the 'Toroceratops' case, the central question is whether it is more plausible to take Triceratops and 
Torosaurus specimens as taxonomically distinct or developmentally distinct. As Longrich \& Field put it,

Before one can use variation to classify species, it is necessary to understand the nature of that variation. That is, do the differences between two fossils represent variation between different species, which is a result of separate evolutionary histories, or do these differences reflect variation within a single species, which can result from variation within a population, sexual dimorphism, or change in morphology over the course of development (Longrich \& Field 1)?

(Notice that Longrich \& Field switch from genera to species, in 6.4 I will discuss the consequences of this argument for higher taxa). To argue that Torosaurus and Triceratops ought to be lumped into the same genus, then, Scannella \& Horner must convince us that the morphological range of the two sets of specimens are more plausibly explained by within-species phenotypic variation, be it due to differences between sexes, between individuals (including pathology) or differences in ontogenetic stage, than by between-species phenotypic variation. Rather than employing a particular species concept, species in paleontology are delineated contrastively, that is, if morphological variation cannot be explained as normal variation within a species, then species (or, as in this case, higher taxa) delineations should be made. And so, although paleo-taxonomies are constructed using morphological data, they are informed by the expected phenotypic diversity of the critters in question. Paleobiologists delineate species membership in terms of the processes which explain variation.

It is important to note that folding Torosaurus into Triceratops is not merely of 'natural paleohistoric' interest, that is, it matters for more than cataloguing Mesozoic fauna. First, it also forms the basis of further hypotheses about Triceratops behavior. If, for instance, Torosaurus are adult Triceratops, why are there so few of them, and what does this tell us about their social organization? Scannella and Horner speculate that either mature Triceratops lived apart from the herd, or that very few made it to full maturity. Moreover, what could be the purpose of such 
phenotypic changes in later life? Here, Scannella and Horner hypothesize that the phenotypic differences functioned in conspecific maturity signaling. Second, it also informs wider discussion of the developmental capacities of Ceratopsidae and dinosaurs generally. If dinosaurs displayed a wide variety of within-species diversity across life stages, it is plausible that dinosaurs are less taxonomically diverse than we thought ${ }^{9}$. Third, the debate feeds into investigations of life's shape. For instance, an essential question in understanding the nature and causes of the K-Pg extinction event is whether dinosaur diversity was decreasing prior to the extra-terrestrial impact event. Whether the impact occurred while dinosaur life was flourishing or in decline tells us about the impact's causal role in the extinction and, potentially, in mass-extinctions generally ${ }^{10}$. Folding together the only two Ceratopsidae genera present at the K-Pg boundary matters here, as does the thought that general dinosaur diversity may have been overestimated. Moreover, if I may speculate, the suggestion that dinosaurs, particularly larger herbivores, displayed extreme phenotypic diversity across life-cycles may explain the puzzlingly high biodiversity of large animals in late-Mesozoic North America. It could turn out that there were many less species than we thought ${ }^{11}$.

In short, the 'Toroceratops' debate is not simply a matter of categorizing specimens, as it feeds into models of Ceratopsidae (and dinosaur generally) developmental patterns, biodiversity in the late-Cretaceous, the behaviour and ecology of Ceratopsidae, and even the nature of macroevolutionary change. Recall that Scannella \& Horner's success or otherwise is not my concern here, but how they illustrate paleobiologists' taxonomic decisions.

Let's summarize the features of paleobiological practice represented by the 'Torosaurus' debate. As opposed to using some species concept or other, paleobiologists delineate species on explanatory grounds. Specifically, do interspecies or intraspecies processes best explain the

\footnotetext{
${ }^{9}$ Indeed, Schott et al (2011) suggest this of pachycephalosaurus.

${ }^{10}$ See Schulte et al (2010) for a view which emphasizes the role of the impact, and Archibald et al (2010) for a view which sees it as one cause amongst many.

${ }^{11}$ See Roberts et al (in press) for discussion of the phenomenon.
} 
range of variation across specimens? That is, taxonomic decisions in paleobiology are made on the basis of which processes best explain morphological differences: sexual dimorphism, pathologies, phenotypic variation, life-stage variation, or speciation. To argue that a specimen represents a new species, a paleobiologist must show that other processes are insufficient to generate the relevant variation, which requires consideration of:
a. Models of ontogenetic development;
b. Models of phenotype variation ${ }^{12}$ and pathology $y^{13}$;
c. Models of sexual dimorphism;
d. Overlap in strata or lack thereof;
e. Fossil reconstruction and interpretation.

Moreover, taxonomic decisions in paleobiology inform various questions of further paleobiological interest, in this case:

f. The ecology, social strategies, and behaviour of species;

g. Large-scale macroevolutionary patterns.

In the next two sections I argue that these lessons show that paleobiological investigation is 'indifferent' to the different species concepts which drove section 2's pluralism, and that this underwrites a new argument for realism about the species category.

\section{Species concepts don't matter.}

Pluralists highlight cases involving more than one, non-equivalent, equally legitimate species concept. The legitimacy of each concepts is derived from its ineliminable use in a legitimate

\footnotetext{
${ }^{12}$ Pian et al (2013), for example, introduce a new extinct platypus species, Odurodon tharalkooschild, largely on the basis that its enormous size outruns the expected phenotypic range of any other platypus.

${ }^{13} \mathrm{~A}$ nice case of an objection to species delineation on the basis of pathology is the suggestion in Barham (2004) that Homo floresiensis, the so-called 'Hobbits', are merely humans exhibiting microcephaly. In fact, taxonomy is the subject of voracious debate in paleoanthropology: see, for instance, the back and forth between Ian Tattersal and Matt Cartmill, which concluded with the memorable Tattersal (2013).
} 
research project. In this section, I argue that, at least sometimes in paleobiology, we see research programmes which are 'indifferent' to species concepts - it doesn't matter which species concept is used. Moreover, at least sometimes this indifference is not simply due to paleobiologists 'making do' with impoverished evidence, but because of the nature of their inquiry.

Indifference is a relation between a research project and a category essential to that project. The relation is instantiated when any legitimate specification of the category makes no difference to the research project. That is, given the method employed, it simply does not matter whether one specification or the other is used, or whether one or the other is 'true'. It is important to distinguish between a project being 'indifferent' to a category, and the category being 'irrelevant'. Presumably, say, differing accounts of 'virtuous agents' are not relevant to paleobiological investigation. It doesn't follow from this that paleobiological investigation is indifferent to the category of 'virtuous agent', because such a category must be employed by the investigation. Paleobiologists, I shall argue, are indifferent to the species category because they are in the business of examining, inferring from, and delineating species, but it doesn't matter whether 'species' is understood according to a particular concept. Although differing ideas of 'virtuous agent' also don't matter to paleobiological investigation, this doesn't count as indifference in my sense because such a category doesn't play a role in paleobiological inquiry ${ }^{14}$.

To demonstrate indifference, then, one must articulate how a category is identified and employed by some research project, and show that the method is applicable across various specifications of that category. In section 3 I attempted the first part of this task, here I show that picking a particular species concept will not change paleobiological method ${ }^{15}$.

\footnotetext{
${ }^{14}$ Thanks to an anonymous referee for distinguishing between 'indifference' and 'irrelevence'.

${ }^{15}$ Brandon Holter has suggested to me that indifference could come in degrees: that is, the identification criteria could matter more on some concept than others. He points to the 'mate recognition' species concept, whereby species are delineated via mating preferences which restrict gene-flow.
} 
Arguments for pluralism turn on a lack of indifference between species concepts in different investigative contexts. From the preliminary glance in section 2, for instance, how we go about understanding asexual taxa depends a lot on which species concept is employed. Microbiology, which deals with such critters, then, is not indifferent to the species category: the biological concept is not suitable, while the phylogenetic sometimes is (microbiologists may be indifferent to other species concepts, of course). In contrast to this, the paleobiological method from section 3 is indifferent to the species category. Why? Because the hypotheses which paleobiologists need to control for in order to establish species-hood would count against species membership on any plausible species concept.

I have two arguments regarding indifference, which each draw on section 3's discussion of paleobiological practice. The first argument shows that species delineation in paleobiology requires controlling for contrast-cases which would be problematic no matter which concept is employed. The second argument points to the investigative concerns of paleobiologists: these tend to operate at a coarser grain than that provided by species concepts, although they are informed by species-level systematics and are prima facie about species. The significance of the latter point will become clear in section 5 when I argue for realism about the species category.

Let's begin with the phylogenetic concept. Here, two organisms are part of the same species if they are part of the same lineage-when they are ancestrally unified. If paleobiologists employ this concept, then, they are inferring from morphological character to clade membership. For simplicity, imagine we have a single fossil specimen $f$, and a single well established species $S$ which $f$ might belong to. Assuming that $S$ is the only plausible known species into which $f$ could fit, we have two possible hypotheses: 
$\mathrm{H} 1: f$ is a member of $S$, that is, $f$ is part of the historical lineage $S^{16}$

$\mathrm{H} 2: \mathrm{f}$ is not a member of $S$, that is, $f$ is not part of the historical lineage $S$

To support H2, and thus declare $f$ a new species, paleobiologists must show that f's morphological characteristics do not fall within the range expected of $S$, that is, demonstrate that, given the phenotypic range of S, it is unlikely that f's characteristics can be explained in terms of S-hood (i.e., the within-species processes that cause polymorphism). This, of course, is precisely what we saw in section 3. And so, if paleobiologists use a phylogenetic concept, this will not affect their methodology.

Now, biological concepts. Here, the inference is from morphological characters to breeding population ${ }^{17}$. The analogue competing hypotheses would be as follows:

$H 1^{*}: f$ is a member of $S$, that is, $f$ is part of breeding population $S$

$\mathrm{H}_{2} * \mathrm{f}$ is not a member of $\mathrm{S}$, that is, $f$ is not part of breeding population $\mathrm{S}$

Like lineages, breeding populations (at least of vertebrates!) share phenotypic characters, and so an inference from morphology to breeding population is partially licensed. Again, to support $\mathrm{H} 2$, paleobiologists must show that membership of $\mathrm{S}$ is not a sufficient explanation of f's morphological divergence from accepted members of S. In other words, they must show that $f$ does not fall within the expected phenotypic, developmental and pathological range of S. Again, paleobiological method is not sensitive to the biological species concept: their practices for distinguishing between species don't turn on whether we use that specification or not.

This is a demonstration that species delineation in paleobiology is indifferent to the species category, at least in terms of the biological and phylogenetic species concepts. Even though as a

${ }^{16}$ One way of stating this would be to claim that $S$ forms a monophyletic clade of which $f$ is a member, or that $S$ is an historical individual of which $f$ is a part.

${ }^{17}$ There is, in fact, one case of fossil organisms caught in an extremely extended coitus interruptus: a group of Eocene turtles (see Joyce et al 2012). 
matter of fact, the two concepts would divide some groups of dinosaurs differently (as some dinosaur breeding populations are probably not monophyletic clades, and some dinosaur monophyletic clades are probably not breeding groups) the inference of paleobiologists does not distinguish between these.

The same goes for other species concepts. Take, for instance, 'ecospecies': species are delineated in terms of their ecological role (although typically these are discussed as 'ecotypes' within interbreeding populations). Here, $f$ is a member of $S$ just in case $f$ falls within the range of ecological function expected of S. As we have already seen, paleobiologists use morphological characteristics as an inroad to various functional ascriptions-i.e., the dramatic changes in Ceratopsidae frill across developmental stages is taken as a signal of relative maturity-and this is true of ecological function as well. Again, in answering this question paleobiologists must decide whether the best explanation of morphological (and thus inferred ecological) divergence is inter- or intra-species.

We should pause to consider morphological species concepts and related similarity-based, or 'phenetic' conceptions. Here, species are conceived in terms of anatomical criteria, or grouped via similarity. This concept is sometimes linked to paleobiology (e.g Kitcher 1984). I think this is a mistake. Consider two types of morphological species concept, 'strong' and 'weak'. 'Weak' concepts use morphological criteria to infer species. 'Species' are not defined in terms of morphological criteria, but those features are used as proxies. The discussion in section 3 shows that this does not do justice to how taxonomic judgments are made in paleobiology. They do not merely infer from morphological criteria, but morphological criteria which are validated given various models of phenotypic, sexual, developmental and pathological variation within the species concerned (plus strata location). To say that paleobiologists make taxonomic decisions via similarity or morphology alone is a gross over-simplification. 'Strong' concepts define species in terms of those characteristics. This does not do justice to the kind of work which 
paleontologists put species delineations to. Scannella and Horner use their new Ceratopsidae taxonomy to inform reconstructions of biodiversity levels prior to the K-Pg boundary, and thus the nature of the extinction event. They also draw on their taxonomic claim to speculate about the nature of Ceratopsidae life-ways and development. Such considerations involve viewing their targets as more than just morphologically similar groups, but as interacting, developing, breeding lineages and populations. The agnosticism inherent in phenetic or morphological species concepts (or pattern cladism, for that matter), then, does not make sense of the work paleobiologists put species to. Paleobiologists, then, are not indifferent to these kinds of concepts. I discuss whether this causes problems in 6.1.

My second claim about indifference is perhaps best read as a response to an objection to the first. The objection goes as follows. Yes, the paleobiological method of inferring species membership is indifferent to the species category, but this is only due to their epistemic situation. Paleobiologists typically find themselves describing species on the basis of biased, incomplete and degraded specimens - they have no choice but to merely apply a contrastive, abductive criteria. If they had better information, it would surely then matter which species concepts were used. This objection agrees that paleobiologists are indifferent, but distinguishes between vindicatory indifference and circumstantial indifference. Indifference is vindicatory when it is at least in part generated by the aims of the research, while circumstantial indifference is due to scientists 'making do' with what they have. Establishing vindicatory indifference is required for the realism of the next section.

Paleobiologists are not only (or even primarily!) interested in reconstructing past environments and organisms, they also seek to explain macro-evolutionary patterns. That is, what forces are to blame for the patterns we identify in the record? This project involves first finding meaningful patterns in paleobiological information: and this can be a daunting task (see Benton 1999, Turner 2009). On the assumption that macroevolutionary patterns are sometimes 
correctly identified, such patterns require explanation. For instance, as we saw, recent work on Ceratopsidae developmental biology has important consequences for our understanding of large-scale events such as the K-Pg extinction. Taxonomic decisions, even at the species level, matter for getting the general shape of these patterns. But only the general shape is required. For instance, seeing whether biodiversity levels decreased towards the K-Pg boundary does not require fine-grained species delineation, only establishing a general trend. This is true of many macro-evolutionary investigations. Here is the point: in such contexts, paleobiological investigation targets 'species' in some coarse, general sense-they are not making claims about particular taxa, but rather those taxa are used as data points to inform a discussion about how the general category behaves.

Consider the debate about species sorting: is there some directionality, some regularity, influencing which species go extinct and which survive? On one extreme, sorting is 'random': extinction is a lottery. On another extreme, species selection is pervasive, that is, species themselves are in evolutionary competition and some have features which both ensure their survival and increase their chances of spawning daughter-species. Paleobiologists tackle this question on several fronts: they simulate speciation events and taxonomic development using computational aids (the classic "MBL" model is an example), construct large-scale taxonomic data sets from fossil finds ${ }^{18}$, and provide more detailed case-studies of apparent competition between particular species. In this debate, what determines the fate of species is the central concern, but getting species delineation accurate to the species-concept level is simply unnecessary. Even with richer access to information, the scale required of inquiries into speciessorting and other macroevolutionary trends makes membership on the species-concept scale irrelevant (see Turner 2011 chapter 5 for an introduction to species sorting). Note that the debate is about species: whether or not the fate of species over macroevolutionary time is random or is

\footnotetext{
${ }^{18}$ Note that paleobiologists frequently represent this information in terms of higher-taxa categories. This is typically because the fossil record is sometimes less biased when considered by genus or family.
} 
subject to selection. However, it is not about particular species taxa. Paleobiologists are interested in a species category which (as we'll see) is more general than that allowed by pluralist anti-realists.

And so, to answer many paleobiological questions, we do need to make species-level taxonomic decisions, but these decisions needn't be particularly accurate. In other words, even if much richer information relevant to make between-species-concept delineations were available, these would make no meaningful difference to many of the projects which paleobiologists are concerned with. In other words, at least some of the time, paleobiological indifference to the species category is vindicatory. Before moving to realism, we should get clear on what I'm going to suggest we should be realists about.

As we've seen, paleobiologists sometimes argue for propositions about particular taxa ('Torosaurus and Triceratops are the same species') and about species generally ('species have differential rates of survival and radiation because there are fitness differences at the species level'). Let's imagine some such claims are true. In virtue of what would they be so? By indifference, it cannot be due to any particular taxa as delineated by a species concept. If, for instance, Scannella and Horner's hypothesis was true just in case it was true by the phylogenetic species concept, this would suggest their project was not indifferent after all.

I want to suggest that the general species category is the target of paleobiological investigation (in section 6.5 we'll discuss whether paleobiologists have their own species concept). First, notice that the kinds of investigations I appealed to in arguing for vindicatory indifference are not about any particular species taxa, but about species in general. Consider the idea that species sorting is explained via species selection, that is, species having differential rates of survival is due to fitness differences between them. Both the explananda and the explanans here are species and their properties, but it is a general claim about species overall. It 
is about neither particular taxa, nor a particular specification. So, paleobiologists are discussing a general category of 'species'-it is this category which l'll argue is real, next section.

But what might such a category be like, how should we characterize it? We must tread somewhat carefully here. Given that various species concepts are supposed to be specifications of the species category, the target of paleobiologists ought to somehow 'contain' those specifications. But this can create real problems. Imagine, for the sake of the argument, that it turned out that Triceratops and Torosaurus are the same species by one species concept, but are different species by another. If the species category is simply the combination of those various legitimate specifications, then the claim that 'Triceratops and Torosaurus is the same species' comes out both true and false. This is not a good result: I don't want to commit to there being true contradictions ${ }^{19}$ ! Happily, there is a solution to this problem. Instead of taking the general category to be the combination of (or perhaps the disjunction of) the various specifications, I can take it as the maximally consistent conjunction of the specifications ${ }^{20}$. That is, we take the largest set of the results of legitimate species specifications which are non-contradictory, and take this as what paleobiological discussion is about ${ }^{21}$. This would avoid contradiction. It also gives us a sense of what kind of category l'm going to suggest exists: the general species category is the maximally consistent conjunction of legitimate species specifications and, at least sometimes, it is the target of paleobiological investigation.

\section{Indifference Realism}

I have argued that paleobiology is indifferent to the species category, which I have characterized as the maximally consistent conjunction of legitimate species specifications. In this section, I argue from this indifference to the category's existence. To do this, I need a principle

\footnotetext{
${ }^{19}$ Thanks to David Leibesman for highlighting this problem.

${ }^{20}$ An analogous move is suggested in Lewis (1978).

${ }^{21}$ It may turn out that some paleobiological claims are indeterminate on this kind of view, and as David Leibesman has pointed out to me, this might involve exploring whether vagueness might undermine the link between practice and ontology.
} 
which connects indifference to realism: why would one take a project's indifference about a category's specifications to be grounds for realism about that category? Recall that the traditional pluralist position drew justification from the legitimacy of the research program in question. Concepts gain legitimacy from the programs requiring them. And, moreover, we should be realists about the categories such concepts pick out for the same reason. My thought is that the species category gains legitimacy in a similar way. Because paleobiological research is indifferent—and indifferent in a vindicatory way—we should be realists about the general species category. I will state the principle, and then defend it.

Indifference principle: when some legitimate investigation is indifferent in regards to some category, in a vindicatory sense, then we ought to be realists about that category.

How does the principle work? Recall that many pluralists reach their ontological conclusions via scientific practice. That is, legitimate scientific categorization practices underwrite claims about the existence or otherwise of those categories. Consider the following from Kitcher. He is comparing two accounts of 'virus', one focusing on morphological patterns, and the other on the genetic properties which in part explain those patterns. He first points out that the two concepts are non-equivalent, and then shifts to ontology.

Our reclassification [from morphological patterns to genetic properties] may prompt us to differentiate viruses that we would have formerly have heaped together, or to regard as mere "variants", organisms previously viewed as of radically different types. But, irrespective of any reforms it may induce, the achievement of an explanatory framework goes hand in hand with a scheme for delineating the "real kinds" in nature (Kitcher 1984, 322).

Although Kitcher's scare quotes suggest a certain hedging on his part, there is a clear link here between the success of a concept, its relationship to an explanatory framework, and ontological claims. It is just the same kind of link which leads us from indifference to realism 
about a category, despite the disunified nature of the category's specifications. There is, then, a parity of reasoning argument to be made for pluralists who accept said link.

Note, importantly, that the indifference principle does not only require that an investigation be indifferent to a category—that various specifications make no difference to practice—but also that the investigation is legitimate, and the indifference is vindicatory. This combination, it seems to me, has just the ingredients required to provide the link between success and ontology. Paleobiological species delineations are part of a successful explanatory framework. If Scannella \& Horner are right, and Torosaurus are mature Triceratops, then presumably they have generated knowledge, and knowledge is about something, and scientific knowledge is about real things. The success of paleobiological practice in species delineation gives reason to think that the species category (not simply the categories picked out by various specifications) exists.

In section $4 \mathrm{I}$ argued that (1) paleobiology is indifferent to the species category. This is to say that various specifications of 'species' do not make a difference to how paleobiologists go about identifying them. (2) That this indifference is vindicatory. That is, at least some of the indifference is due to the research target, not merely to epistemic or pragmatic constraints. I take it we can assume (3) that paleobiological research interests are legitimate. If the indifference principle is true, then, we have an argument for realism about the species category even if the category is not unified (that is, there is no one account which captures it).

As I see it, the anti-realist about the species category faces a dilemma. To deny the indifference principle, they must deny that paleobiological indifference is vindicatory, or that paleobiology is legitimate, or reject the link between scientific practice and ontology. In a sense, this is unsurprising. Pluralism is founded on a naturalist philosophical methodology, and in essence my argument seeks to legitimize the species category in virtue of that method: employment by a successful science is a route to ontological legitimacy. The first two anti-realist 
options require delegitimizing paleobiological practice, and the third denies the very epistemology which pluralism is founded ${ }^{22}$.

A final point: it may of course be that, in some contexts, paleobiologists do concern themselves with questions where species-concepts matter, and perhaps in some contexts they do have the information required to delineate between them. This is not necessarily a problem for my argument, as all that is required is that at least sometimes (and important sometimes) paleobiological work is indifferent to species concepts.

And so, we should be realists about the general species category, even though it is in a sense disunified, that is, precisified by a plurality of non-equivalent concepts.

\section{Objections}

I have staked out three different kinds of claim in this paper. First, a claim about paleobiological practice. Specifically, paleobiologists delineate between species on the basis of explanatory criteria. To show that a specimen is deserving of a new species name, it must be shown that intraspecies processes rather than interspecies processes better account for the relevant range of variation between it and other specimens. Second, a claim about naturalist routes to ontology. Specifically, when a legitimate investigation is indifferent to a set of nonequivalent specifications of a category, in a vindicatory sense, we have grounds to be realists about that category in spite of its disunity. Third, these are combined to make a claim about the species category. Specifically, that paleobiological practice is indifferent to the species category (claim one), and that indifference provides reason for realism (claim two), shows that we should be realists about the species category. I think that these claims can be challenged in fruitful ways, so I want to finish by briefly considering a set of objections.

\footnotetext{
${ }^{22}$ Naturally, for epistemic anti-realists such as Stanford and Rosenberg, this is less pressing. Although, if they are realists about various taxa which species concept pick out, there remains a tension.
} 


\subsection{Paleobiologists are not indifferent to all species concepts.}

Perhaps paleobiologists are indifferent to some, but not all, legitimate species concepts. For instance, it could turn out that pattern cladism or pheneticism play an important role in some research program or other. If my argument in section 4 is right, then how paleobiologists delineate species does not cohere with those concepts. If that turns out to be the case, then it seems I cannot claim to have established the existence of the species category, as it includes some, but not all, species concepts.

We should not get too caught up in what we call a 'species', establishing the existence of a general (but disunified!) category is what matters here (see footnote 7). If there are some legitimate species concepts for which paleobiology is not indifferent, then my argument establishes taxa-category realism, rather than species realism. Having said this, I'm not convinced that pattern cladism or pheneticism do underwrite legitimate research programs. For this objection to bite, it must be established that there is a species concept such that (1) paleobiology is not indifferent to it, and (2) it underwrites a legitimate research program. If this was achieved, I would happily give up my talk of the 'species' category, and be content to have established the existence of a taxa category ${ }^{23}$.

More generally, the answer to this kind of objection is further examination of scientific practice, and of course there is a limit to how much can be managed in a paper of this nature.

\subsection{Is it the same species category for everyone?}

A related, and I think important, objection asks whether the species category established by paleobiological practice does the job of unifying biological systemization ${ }^{24}$. That is, when we commit to the species category, we are supposed to be committing to a general target of

\footnotetext{
${ }^{23}$ Marc Ereshesfsky raised this objection.

${ }^{24} \mathrm{I}$ am thankful to an anonymous referee for raising this objection.
} 
biological investigation. But if we are realists about the particular taxa picked out by various species concepts, surely some biologists simply mean something else by 'species' than the paleobiologists do. I'm not convinced that unifying biological discussion of species ought to be a criteria for realism about a general species category, but regardless think that there is at least some reason to think that paleobiological practice does, in fact, achieve this.

The force of my response, I think, turns on the scope of paleobiological investigation. When I argued that paleobiological indifference is vindicatory, I highlighted the large-scale questions they ask. Paleobiologists grapple with the shape of life on the macro-scale. This includes asking whether, and on what grounds, life's history could have been different: how contingent or determinate (and based on what) are the fates of taxa? Such questions, it seems to me, potentially unify biological investigation of species insofar as they are on the broadest relevant scale. Other biological investigations, say into the development and evolutionary history of viruses which Kitcher discussed, pick out valid sub-sets of the general kind 'species', engineered to the smaller-scale inquiry at hand. By examining species at the broadest level, inclusive of (and indifferent to) the various specifications required for finer grained biological investigations, paleobiology does do significant unificatory work.

This response is speculative and establishing it (or undermining it) would involve a deeper examination of scientific practice. Specifically, are there legitimate investigations who target species concepts which fall outside of paleobiology's remit, or alternatively is there a broader category still?

\subsection{Weird categories cannot exist.}

There might be something wrong a priori with establishing the existence of the kind of category l've discussed: one which consists in the maximally consistent conjunction of a set of 
specifications $^{25}$, where the specifications are non-equivalent. If someone outright rejects the possibility of such categories, then my argument still shows us something. Either the species category is unified after all—pluralism is false-or paleobiology is illegitimate. After all, if paleobiology is legitimate, and that research programme is indifferent to species concepts, and there are no categories like that, then the species category must be unified. If paleobiology is indifferent to species concepts, and pluralism is true, and there are no such categories, then paleobiology must be illegitimate. I'm not sure which of these paths are better, or why they would be preferable to simply accepting these categories into one's ontology.

However, making ontological decisions on a priori grounds is not in the spirit of the species debate. Ontological claims come from scientific practice, not from preconceived notions of what there is or what there must be. After all, it is the use of various species concepts in scientific practice which underlies pluralism in the first place, and so it would be odd for pluralists to abandon the naturalist underpinnings of their own position. A legitimate, successful science is indifferent to various species concepts and so, if the argument from 5 goes through, pluralists should commit to the existence of the species category —and to other disunified categories meeting the same criteria.

Pluralists unhappy with this conclusion should re-evaluate the link between practice and ontology. Indeed, some might take my argument as a reductio against such a link! Just what is required to draw ontological conclusions from scientific practice? If the analogy between

\footnotetext{
${ }^{25}$ This kind of objection could be made via appeal to work from the philosophy of mind on disjunctive properties. Hilary Putnam (1967), Ned Block and Jerry Fodor (Block \& Fodor 1972, Fodor 1974) have argued that disjunctive kinds are illegitimate. In that context, the argument centers on the nature of multiplerealizability: a large number of different substrates, in different arrangements, could potentially have what it takes to be a particular propositional attitude. It is likely, for instance, that a different neural correlate is involved with my thinking $x$ than for your thinking $x$. However, it seems as if we can think the same $x$, that is, our xs can have the same content. If so, then either propositional attitudes should be characterized functionally (or in some other non-reductive way), or the identity theorist may accept a disjunction of those various substrates as a real kind. In rejecting identity-theory, then, philosophers of mind have argued against admitting disjunctive kinds into our ontology.
} 
pluralism and indifference is broken, my argument would collapse. However, to do so, they must tell us which features of indifference block ontological conclusions, and why.

\subsection{Higher taxa.}

The debate about the taxonomic relationship between Triceratops and Torosaurus is in part about genera, not species. Does this argument then commit us to the existence of higher taxa as well? I suspect so, but with reservations. First, to repeat myself, focussing on what gets to be called a 'species' is not an interesting debate. I am happy to be a 'taxa-category' realist and be done with it.

Second, recall that my case study is representative of how species delineations are made in paleobiology. It does not follow from paleobiologists using the same method to identify different levels of taxa that arguments about one taxa carry over to another. What matters is the role such taxa play in paleobiological work: remember, it is the borrowed legitimacy from scientific practice which grants realism. Moreover, the indifference must be vindicatory: scientists must be appealing to higher taxa not due to circumstance, but due to their investigative target. A fuller investigation of paleobiological practice would be required to determine whether higher-taxa categories were also treated indifferently and in a vindicatory manner. I suspect that some will be, for instance the phylum-level importance of 'body-plans' has been a foundational for paleobiology. I leave that investigation for later work ${ }^{26}$.

\subsection{A species concept for paleobiology?}

Finally, there is a pressing objection to my claim that paleobiological practice is indifferent to species concepts. Surely, rather than picking out a general species category, or a disjunction or

\footnotetext{
${ }^{26}$ Marc Ereshefsky raised this objection.
} 
conjunction of different species concepts, they simply have their own concept ${ }^{27}$ ? If so, then we do not get a general species category, but instead yet another sub-category—-the paleobiological one. But what would the paleontological species concept look like?

I have been discussing concepts as being (something like) instructions for carving up the world. They are functions which take us from states of affairs to categories. The biological species concept, for instance, takes us from facts about interbreeding populations to species delineations. Paleobiologists do not apply a criteria like this to establish species membership or otherwise. Rather, they examine the spread of variation between specimens and ask whether the best explanation of said variation appeals to interspecies factors or intraspecies factors. This is not a concept, a recipe for producing categories from states of affairs. Rather, it is an abductive practice for determining species membership. But 'species' in what sense? The point of indifference is that it would be a mistake to identify paleobiological discussion of species with any particular species concept. Their method is not sensitive to which species concept is employed. Moreover, this indifference is vindicatory, it is at least sometimes due to the kinds of questions paleobiologists ask (as opposed to their underprivileged epistemic status). This suggests that, despite not using a concept as I have understood it here, the link from practice to ontology is maintained. Paleobiologists do not have a species concept, but they do generate knowledge about species. And not only knowledge about particular taxa, but about how species generally behave in macroevolution. What else might this knowledge be about, if not a general species category?

\section{Conclusion}

I have argued for realism about the species category (being the maximally consistent conjunction of species specifications) on grounds of paleobiological practice. Because

\footnotetext{
${ }^{27}$ Thanks to an anonymous referee for raising this objection.
} 
paleobiologists generate knowledge about their subjects, and because their subjects are sometimes species (but not species according to any particular species-concept), we should believe in the species category. This argument relies upon the notion of 'indifference'. This notion, and its relation to realism through the argument from section 5, is ripe for application in other areas. I also hope to have shown in section 6 that, if I am wrong, I am wrong in interesting and fruitful ways. Finally, this paper has a message for paleobiologists who are perhaps less concerned about issues of realism: don't worry about species-concepts.

\section{Bibliography}

Andam, Cheryl P. ; Williams, David \& Gogarten, J. Peter (2010). Natural taxonomy in light of horizontal gene transfer. Biology and Philosophy 25 (4):589-602.

Archibald, J. D., Clemens, W. A., Padian, K., Rowe, T., Macleod, N., Barrett, P. M., ... \& Sahni, A. (2010). Cretaceous extinctions: multiple causes. Science (New York, NY), 328(5981), 973-975

Avise, J. C., \& Wollenberg, K. (1997). Phylogenetics and the origin of species. Proceedings of the National Academy of Sciences, 94(15), 7748-7755.

Baker, H. G. (1952). The ecospecies-prelude to discussion. Evolution, 61-68.

Bapteste, Eric \& Burian, Richard M. (2010). On the need for integrative phylogenomics, and some steps toward its creation. Biology and Philosophy 25 (4):711-736.

Bapteste, E., O’Malley, M. A., Beiko, R. G., Ereshefsky, M., Gogarten, J. P., Franklin-Hall, L., ... \& Martin, W. (2009). Prokaryotic evolution and the tree of life are two different things. Biol Direct, 4(1), 34 .

Barham, L. (2004). Some initial informal reactions to publication of the discovery of Homo floresiensis and replies from Brown \& Morwood. Before Farm, 4, 1-7. 
Baum, D. A., \& Shaw, K. L. (1995). Genealogical perspectives on the species problem. Experimental and molecular approaches to plant biosystematics, 53, 289-303.

Benton, M. J. (1999). The history of life: large databases in palaeontology. Numerical palaeobiology, 249-283.

Block, N. J., \& Fodor, J. A. (1972). What psychological states are not. The Philosophical Review, 159-181.

Brigandt, I. (2003). Species pluralism does not imply species eliminativism. Philosophy of Science, 70(5), 1305-1316.

Currie, P. J. (1998). Possible evidence of gregarious behavior in tyrannosaurids. Gaia, 15, 271277.

De Queiroz, K. (1999). The general lineage concept of species and the defining properties of the species category. Species: new interdisciplinary essays, 49-89.

Dobzhansky, T. (1937). Genetics and the Origin of Species. New York: Columbia University Press.

Dupré, J (1999). "On the impossibility of a monistic account of species". In Wilson, RA. Species: New Interdisciplinary Essays. Cambridge, MA: MIT Press. pp. 3-22

Dupré, J., 1993, The Disorder of Things: Metaphysical Foundations of the Disunity of Science, Cambridge, Massachusetts: Harvard University Press.

Ereshefsky, M., 2001, The Poverty of the Linnaean Hierarchy: A Philosophical Study of Biological Taxonomy, Cambridge: Cambridge University Press.

Ereshefsky, M. (2010). Microbiology and the species problem. Biology \& Philosophy, 25(4), 553-568. 
Ereshefsky, Marc (1998). Species pluralism and anti-realism. Philosophy of Science 65 (1):103-120.

Erickson, G. M., Makovicky, P. J., Currie, P. J., Norell, M. A., Yerby, S. A., \& Brochu, C. A. (2004). Gigantism and comparative life-history parameters of tyrannosaurid dinosaurs. Nature, 430(7001), 772-775.

Farlow, J. O. (1990) Dinosaur energetics and thermal biology. IN: Weishampel, Dodson \& Osmolska (eds). The Dinosauria. University of California Press, Berkely: pp. 43-55

Fodor, J. A. (1974). Special sciences (or: the disunity of science as a working hypothesis). Synthese, 28(2), 97-115.

Funk, D. J., \& Omland, K. E. (2003). Species-level paraphyly and polyphyly: frequency, causes, and consequences, with insights from animal mitochondrial DNA. Annual Review of Ecology, Evolution, and Systematics, 397-423.

Ghiselin, M. (1987). Species concepts, individuality, and objectivity. Biology and Philosophy 2: $127-143$

Horner, J. R., \& Lamm, E. T. (2011). Ontogeny of the parietal frill of $<\mathrm{i}>$ Triceratops</i>: A preliminary histological analysis. Comptes Rendus Palevol, 10(5), 439-452.

Hull, D., 1988 , Science as a Process, Chicago: University of Chicago Press.

Joyce, W. G., Micklich, N., Schaal, S. F., \& Scheyer, T. M. (2012). Caught in the act: the first record of copulating fossil vertebrates. Biology letters, 8(5), 846-848.

Kitcher, P., 1984, "Species”, Philosophy of Science, 51: 308-333.

Lewis, D. (1978). Truth in Fiction. American Philosophical Quarterly. Vol. 15, No. 1 pp. 37-46. 
Longrich, N. R., \& Field, D. J. (2012). Torosaurus is not Triceratops: ontogeny in chasmosaurine ceratopsids as a case study in dinosaur taxonomy. PloS one, 7(2), e32623.

Maiorino, L., Farke, A. A., Kotsakis, T., \& Piras, P. (2013). Is Torosaurus Triceratops? Geometric Morphometric Evidence of Late Maastrichtian Ceratopsid Dinosaurs. PloS one, 8(11), e81608.

Mayr, Ernst (1942). Systematics and the origin of species from the viewpoint of a zoologist. New York: Columbia University Press.

Mishler, B. and Brandon, R., 1987, "Individuality, Pluralism, and the Phylogenetic Species Concept", Biology and Philosophy, 2: 397-414.

O'Malley, M., Dupré, J., 2007, “Size doesn't matter: towards a more inclusive philosophy of Biology”, Biology and Philosophy, 22: 155-191.

Paterson, H. (1985). The recognition concept of species. In Vrba (ed), species and speciation. Pretoria: transvall museum, pp, 21-29.

Pian R, Archer M , Hand S J (2013). A new, giant platypus, Obdurodon tharalkooschild, SP. Nov. (Monotremata, Ornithorhynchidae) from the Riversleigh world heritage area, Australia. J Vertebr Paleontol 2013; 33: 1255-1259.

Putnam, H. (1967). Psychological predicates. Art, mind, and religion, 37-48.

Roberts, E M., Sampson, S. D., Deino, A., and Bowring, S. in press. The Kaiparowits Formation: a remarkable record of Late Cretaceous terrestrial environments, ecosystems and evolution in Western North America. In A. L. Titus and M. A. Loewen (eds.), Advances in Western Interior Late Cretaceous Paleontology and Geology. Indiana University Press, Bloomington.

Reydon, T. A.C. (2004), Why does the species problem still persist?. Bioessays, 26: 300-305. doi: 10.1002/bies.10406 
Scannella, J. B., \& Horner, J. R. (2010). Torosaurus Marsh, 1891, is Triceratops Marsh, 1889 (Ceratopsidae: Chasmosaurinae): synonymy through ontogeny. Journal of Vertebrate Paleontology, 30(4), 1157-1168

Scannella, J. B., \& Horner, J. R. (2011). 'Nedoceratops': An example of a transitional morphology. PloS one, 6(12), e28705.

Schott, R. K., Evans, D. C., Goodwin, M. B., Horner, J. R., Brown, C. M., \& Longrich, N. R. (2011). Cranial ontogeny in Stegoceras validum (Dinosauria: Pachycephalosauria): a quantitative model of pachycephalosaur dome growth and variation. PloS one, 6(6), e21092.

Schulte, P., Alegret, L., Arenillas, I., Arz, J. A., Barton, P. J., Bown, P. R., ... \& Willumsen, P. S. (2010). The Chicxulub asteroid impact and mass extinction at the Cretaceous-Paleogene boundary. Science, 327(5970), 1214-1218.

Sober, E., 1984, "Sets, Species, and Natural Kinds: A Reply to Philip Kitcher's 'Species”", Philosophy of Science,51: 334-341.

Stanford, P. K. (2006). Exceeding our grasp: Science, history, and the problem of unconceived alternatives. Oxford University Press.

Tattersall, I. (2013), Higher taxa: Reply to cartmill. Evol. Anthropol., 22: 293

Turner, Derek D. (2011). Paleontology: A Philosophical Introduction. Cambridge University Press.

Turner, D. D. (2009). How much can we know about the causes of evolutionary trends?. Biology \& Philosophy, 24(3), 341-357.

Wilkins, J., 2009, Species: The history of the idea, Berkeley: University of California Press. 
Wilkins, J., 2003, "How to be a chaste species pluralist-realist", Biology and Philosophy, 18: 621-638. 